\title{
A model for Shaping the Focus and Content of Cross-Cultural Orientation and Training (CCOT) Programs in HEIs in the United Arab Emirates
}

\author{
Dr David Kwame Quansah \\ Abu Dhabi Men's College \\ Higher Colleges of Technology \\ United Arab Emirates
}

\begin{abstract}
The purpose of this paper is to develop a model for shaping the focus and content of Cross-Cultural Orientation and Training (CCOT) programs for expatriate academics in higher education institutions (HEIs) in the UAE. The research design used for the study was the mixed method approach using a sequential technique. A total of 324 expatriate academics employed in three HEIs in the UAE responded to the questionnaire, and 57 of them participated in face-to-face interviews. Pearson product moment correlation, multiple regression, ANOVA, Survey Monkey's categorize feature (text analysis), and content analysis approach (general inductive approach)were employed in analyzing the data. The results of this study confirmed that CCOT programs made a significant unique contribution to expatriate academics' cross cultural adjustment and their intention stay. The findings also revealed that five distinct content areas were identified by incumbent expatriate academics as being the most important content areas to be included in any CCOT program. The scope of each content area is explained and discussed in this paper. In many instances, these five content areas overlap in regards to the issues that they address, and are in some cases interrelated. Although the purpose of this study is not to generalize, the researcher suggests future research involving host country nationals, students, faculty recruitment specialists, and CCOT specialists or consultants. By expanding the sample size and including various parties or stakeholders including different methodologies for data collection, this topic can be explored further, and the range of issues discussed in this paper can be expanded.
\end{abstract}

Keywords: Cross-Cultural Adjustment, Cross-Cultural Orientation and Training, Expatriate Academics, Expatriate Adjustment, Higher Education Institutions.

\section{Introduction}

The United Arab Emirates (UAE) has experienced an overwhelming growth in the education sector, for example, in 2016; the UAE had the second highest percentage of the world's international branch campuses (Garrett, Kinser, Lane, and Merola, 2016). Unfortunately, this tremendous growth is not matched by the number of available host country nationals (HCNs) qualified as academic staff in the region (Tripathi and Mukerji, 2008). The overwhelming demand for higher education in the UAE from both Emirati citizens and expatriates, and the simultaneous lack of qualified academics, has also led to the recruitment of expatriate academic staff (Badry and Willoughby, 2015; Clarke, 2015; Knight, 2011, 2013). According to MOHESR (2014), the faculty population at UAE's federal and CAA-licensed institutions is highly diverse with only $6.32 \%$ HCNs. This demographic confirms the role of expatriate academics in achieving the UAE's national development and global competitiveness targets. It also indicates that the higher education institutions are going to have to deal with crossculture issues and challenges. Most importantly, it highlights the crucial importance of cross cultural management and expatriate adjustment studies to the UAE in the field of higher education. This situation (shortage of HCNs as academics) is not unique to the UAE but other countries like Saudi Arabia, Qatar, Kuwait (Clarke, 2015; Sanderson, 2014). The United Kingdom (Miller, 2009; 2010), Taiwan (Liao, 2010), and Hong Kong (Chan, 2015; $\mathrm{Chu}, 2009$ ) have resorted to the recruitment of expatriate academics in certain subject areas. Despite the benefits of hiring expatriates, the whole expatriation process is not without challenges to the undertaker and the host organisations (Mahfouzand Ahmed, 2010; Miller, 2009, 2010; Richardson, 2000; Selmer and Luring, 2011). Generally, adjustment is one of the toughest challenges facing all expatriates (Clarke, 2015; Miller, 2009, 2010; Richardson and McKenna, 2002). 
The decision to relocate to a different country comes with many challenges (Sanderson, 2014), for example, being cut off from one's familiar social networks while simultaneously trying to acclimatize to a new host culture and job situation nurtures a sense of isolation and causes stress (Berry, 2005; Miller, 2009). Anxiety, depression, and apathy are also other symptoms of expatriate stress (Miller, 2009, 2010; Swagger and Ellis, 2003). At the organisations level, expatriate maladjustment can lead to conflict, financial loss, poor job performance, lack of job satisfaction, less organizational commitment, high turnover, and early return to home country (Black and Stephens, 1989; Hofstede, 2001; Miller, 2009). Time is often lost when organisations seek replacements because finding a suitable replacement might be difficult (Mussel in, 2004). Just like "traditional" expatriates, expatriate academics encounter widespread difficulties in their new environment (Miller, 2009, 2010; Selmer and Luring, 2011). Recent studies showed that the challenges faced by expatriate academics originate from the general environment, work environment, and social interaction (Selmer and Luring, 2011; Clarke, 2015; Attach, 2016). Academics working abroad encounter several constraints with regards to cultural and language misunderstandings and barriers, setting up new home, integrating with locals, settling in the family, stress and alienation (Clarke 2015; Richardson and McKenna, 2002). These difficulties sometimes hinder or have the potential to negatively affect their motivation, job satisfaction, performance, participation, and intention to stay. Research has shown that expatriate academics in higher education institutions (HEIs) in the UAE encounter widespread difficulties in their new environment (Attach, 2016; Clarke 2015; Knight, 2011, 2013).

Studies by Miller (2009, 2010) and Selmer and Luring (2016) viewed cross-cultural orientation and training (CCOT) as having the potential to contribute to the expatriates' cross-cultural adjustment. Black and Mendenhall (1990) concluded their review by stating that cross-cultural training enables sojourners to develop skills and successfully complete their cross-cultural assignments. Tung (1981) pointed out that the CCOT requires a certain extent of modification based on the nature of the overseas assignment and the host culture. CCOT might be effective depending on the host nation, individual expatriate and the contextual factors of the foreign assignments included in the orientation or training (Selmer, 2004; Caligiuri, and Tarique, 2016). Such programs raise the realistic expectations of the expatriates and thus help lower their stress during the cross-cultural adjustment process. Having accurate expectations regarding the future job has a positive effect on cross-cultural adjustment (Caligiuri et al., 2001), it makes them better prepared for the new environment which is not familiar to them (Caligiuri, and Tarique, 2016; Kraimer, Bolino, and Mead; 2016; Zhang, and Peltokorpi, 2016).This study provides evidence for HEIs to develop effective CCOT programs that ensure expatriate academics form realistic expectations of their overseas jobs.

\section{Research Problem}

Even though several studies have demonstrated the significance of CCOT (e.g. Black and Mendenhall, 1990; Caligiuri, 2000; Deshpande and Viswesvaran, 1992; Johnson, Lenartowicz and Apud, 2006; Tung, 1981, 1982), the majority of organizations and their top managements still doubt its importance or deliberately neglect it. According to Clarke (2015) there is often lack of preparation provided to expatriate academics that will enable them successfully adjust to their new environment. In a study conducted by Chu (2009) it was reported that there were inadequacies in the provision of suitable cross-cultural preparation, induction, training and ongoing support provided for expatriate teachers.

Expatriate management constitutes an extensive area of academic research interest (Forster, 1997, p.4; McNulty and Selmer, 2017), however, much of what is known about expatriate academics is still largely based on expatriate corporate executives (Clarke, 2015; Kreber and Hounsell, 2014; Selmer and Lauring, 2011; Sanderson, 2014). With regards to the UAE, only a limited number of studies have been completed on expatriate adjustment in higher education (Clarke, 2015). Isakovic and Whitman (2013), Knight (2013), and Sanderson (2014) also argue that further research is required in order to assess and evaluate the challenges, complexities and environment the foreign academics in the UAE are facing.

\section{Purpose and Research Questions}

Based on the above arguments, it is clear if these challenges are not addressed, HEIs in the UAE might not be able to fully exploit the knowledge, skills, and experiences that expatriate academics bring with them. The purpose of this paper is to develop a model for shaping the focus and content of CCOT programs for expatriate academics in HEIs in the UAE. This paper will attempt to answer the following questions: 
a) What are incumbent (current) expatriate academics' opinions on the knowledge, skills, and abilities required for expatriate academics to successfully adjust to working and living in the UAE?

b) What insights into the content of a CCOT program are given by current expatriate academics working and living in the UAE?

By answering these questions, this paper will be able to make suggestions for intervention for HEIs by assisting their administrators, managers, and human resource practitioners in developing and or improving their CCOT programs thereby helping expatriate academics in HEIs in the UAE to better cope with cross-cultural challenges.

\section{Methodology}

The research design used for the study was the mixed method approach using a sequential technique. The population comprised expatriate academics in HEIs in the UAE while the target population was made up of expatriate academics working in three higher education institutions, a public HEI in Abu Dhabi and two private HEIs in Dubai. 324 expatriate academics were purposively sampled for the study. $63.6 \%(\mathrm{n}=206)$ were expatriate academics working in a public HEI and $36.4 \%(\mathrm{n}=118)$ were expatriate academics working in a private HEIs. These HEIs are either single-sex or mixed-sex (setting). The instruments for data collection were based on Black and Stephens' (1989) sociocultural adjustment questionnaire scales, Trompenaars and HampdenTurner's (1998) dimension of culture, and a literature study. Black and Stephens' (1989) sociocultural adjustment questionnaire scales is the most often used measurement of expatriate adjustment (Bhaskar-Shrinivas et al., 2005) whose application has delivered significant empirical evidence on expatriate adjustment (Alshammari, 2013; Gullekson, and Dumaisnil, 2016; Hechanova et al., 2003; Liao, 2010; Mendenhall et al., 2002). Several studies (Isakovic and Whitman, 2013; Ward, Leong, and Low, 2004; Liao, 2010) have also confirmed the reliability and validity of Black and Stephens' (1989) questionnaire scales. The instruments were modified based on the literature reviewed and previous research (e.g. Chan, 2008; Chu, 2009; Liao, 2010; Alshammari, 2013; Palmer, 2013; Chan, 2015).

\section{Results}

Pearson product moment correlation, multiple regression, ANOVA, Survey Monkey's Categorize feature (Text Analysis), and content analysis approach (general inductive approach)were employed in analyzing the data. The analysis was done in line with the research questions. The analysis of the bio-data showed that the respondents used for the study were made up of $54.3 \%(n=176)$ female and $45.7 \%(n=148)$ male, suggesting that more female expatriate academics participated in the study. Considering the age of the respondents, it was found out that majority of the participants were middle-aged (35-54) compared to those who were in their mid-twenties to thirties $(25-34$ years) $(n=5,1.5 \%)$ or older $(55-64$ years $)(n=53,16.4 \%)$. The proportion of those who were married $(n=264,81.5 \%)$ greatly exceeded those who were either divorced $(n=41,12.7 \%)$, single $(n=14,4.3 \%)$, separated $(\mathrm{n}=3,0.9 \%)$ or widowed $(\mathrm{n}=2,0.6 \%)$. The majority of the married respondents were accompanied by their spouses $(n=250,77.2 \%)$, about $35 \%$ more than those who did not $(n=41,12.7 \%)$ and $10.2 \%(n=33)$ found this item inapplicable. A great majority $(\mathrm{n}=283,87.3 \%)$ had at least one child compared to those who had none $(\mathrm{n}=41,12.7 \%)$. With regards to nationality, it was found out that majority of the participants $(\mathrm{n}=196)$ representing 60.49\% were from Western countries (i.e. the United States, Great Britain, Australia, Germany, Ireland, Canada, New Zealand, Denmark, Austria, Poland, Romania, Greece, France, Italy, Spain, Hungary), while $17.28 \%(n=56)$ were from Arabic speaking countries (i.e. Egypt, Iraq, Jordan, Lebanon, Sudan, Syria, Tunisia, Yemen). The Asian participants $(\mathrm{n}=40)$ were from the Philippines, Thailand, India, Korea, Pakistan, and Turkey and made up $12.34 \%$ of the total population, and another $7.72 \%(\mathrm{n}=25)$ were from South Africa. The rest of the participants $(\mathrm{n}=7)$ representing $2.16 \%$ were from Benin, Congo-Brazzaville, Colombia, Jamaica, Kenya, Mexico and Nigeria. In order to assert the relevance of CCOT on expatriate academics in HEIs in the UAE, Multiple Regression and ANOVA was employed in analyzing the data.

\subsection{Significance of CCOT}

The multiple regression results in Table 1 showed that among the variables, it was cross-cultural orientation/training that made a significant unique contribution $(\beta=-.114, \mathrm{p}=.040)$ whilst cross-cultural experience $(\beta=.108, \mathrm{p}=.052)$ did not contribute significantly to their intention stay.

This result established that even though anticipatory adjustment contributed to expatriate academics' intention to stay in the UAE, it was CCOT programs that were critical to determine intention to stay. 
Table 1: Multiple Regression and ANOVA Results for Anticipatory Adjustment and Intention to Stay

\begin{tabular}{|c|c|c|c|c|c|c|c|c|c|}
\hline Model & & $\begin{array}{l}\text { Sum of } \\
\text { Squares }\end{array}$ & $\mathrm{df}$ & $\begin{array}{l}\text { Mean } \\
\text { Square }\end{array}$ & $\mathrm{F}$ & Sig. & $\beta$ & $\mathrm{t}$ & $\mathrm{p}$ \\
\hline \multirow[t]{3}{*}{1} & Regression & .680 & 2 & .340 & 4.197 & .016 & & & \\
\hline & Residual & 25.990 & 321 & .081 & & & & & \\
\hline & Total & 26.669 & 323 & & & & & & \\
\hline (Constant) & & & & & & & & 21.689 & .000 \\
\hline CCE & & & & & & & .108 & 1.953 & .052 \\
\hline $\mathrm{CCO} / \mathrm{T}$ & & & & & & & -.114 & -2.064 & .040 \\
\hline $\mathrm{R}$ & .160 & & & & & & & & \\
\hline $\mathrm{R}^{2}$ & .025 & & & & & & & & \\
\hline Adj. $R^{2}$ & .019 & & & & & & & & \\
\hline Std. Error & .285 & & & & & & & & \\
\hline
\end{tabular}

\subsection{Relevant Content Areas for a CCOT program}

The Multiple Regression was carried to assess the contribution of all cross-cultural variables to intention to stay. The multiple regression results for the influence of the variables for general adjustment in Table 2 revealed that all the components of general environment accounted for $12.2 \%$ variance in expatriate academics' intention to stay and significant $[\mathrm{F}(8,315)=5.458, \mathrm{p}=.000]$ at 0.05 alpha level. However, further investigation revealed that health care facilities $(\beta=.180, p=0.003)$, entertainment/recreation facilities and opportunities $(\beta=-.225, p=0.001)$, and weather $(\beta=.154, p=0.028)$ did make unique significant contribution to intention to stay. Therefore, it was concluded that general environment, health care facilities, entertainment/recreation facilities and opportunities and weather related topics are important content areas for a CCOT program.

Table 2 Multiple Regression and ANOVA Results for General Environment Factors and Intention to Stay

\begin{tabular}{|c|c|c|c|c|c|c|c|c|c|}
\hline \multirow[b]{2}{*}{ Model } & \multicolumn{2}{|l|}{ Sum Of } & \multicolumn{2}{|l|}{ Mean } & \multirow[b]{2}{*}{ Sig. } & \multirow[b]{2}{*}{$\beta$} & \multirow[b]{2}{*}{$\mathrm{t}$} & \multirow[b]{2}{*}{$\mathrm{p}$} & \\
\hline & Squares & $\mathrm{df}$ & Square & $\mathrm{F}$ & & & & & \\
\hline 1 & Regression & 114.216 & 8 & 14.277 & 5.458 & .000 & & & \\
\hline & Residual & 824.007 & 315 & 2.616 & & & & & \\
\hline & Total & 938.222 & 323 & & & & & & \\
\hline 1 & (Constant) & & & & & & & 2.087 & .038 \\
\hline & Food & & & & & & .056 & 1.001 & .318 \\
\hline & $\mathrm{HF}$ & & & & & & .180 & 2.944 & .003 \\
\hline & Ent. & & & & & & -.225 & -3.370 & .001 \\
\hline & CL & & & & & & -.037 & -.512 & .609 \\
\hline & Shopping & & & & & & -.020 & -.330 & .742 \\
\hline & $\mathrm{HC}$ & & & & & & .032 & .448 & .654 \\
\hline & Weather & & & & & & .154 & 2.210 & .028 \\
\hline & Transp. & & & & & & .095 & 1.498 & .135 \\
\hline $\mathrm{R}$ & .349 & & & & & & & & \\
\hline $\mathrm{R}^{2}$ & .122 & & & & & & & & \\
\hline $\begin{array}{l}\text { Adj. } \\
\mathrm{R}^{2}\end{array}$ & .099 & & & & & & & & \\
\hline $\begin{array}{l}\text { Std. } \\
\text { Error }\end{array}$ & 1.617 & & & & & & & & \\
\hline
\end{tabular}

Table 3 also disclosed that collectively, all the social adjustment factors contributed $73.5 \%$ variance in staff's intention to stay which was assessed to be statistically significant $[F(9,120)=37.021, p=.000]$ at 0.05 alpha level. There was a $2 \%$ drop in the population value which suggested that the regression model performed fairly well in describing expatriate academics' intention to stay in the country. However, the information pointed out that living conditions in general $(\beta=0.367, p=0.000)$, interacting with host nationals outside of one's organization $(\beta=0.237, p=0.012)$, interacting with host nationals on a day-to-day basis at work $(\beta=0.307, p=0.000)$, interacting with Emirati students $(\beta=0.145, p=0.022)$, and relationship with immediate line manager $(\beta=0.107, p=0.030)$ 
Table 3: Multiple Regression and ANOVA Results for Social Adjustment Factors and Intention to Stay

\begin{tabular}{|c|c|c|c|c|c|c|c|c|c|}
\hline Model & $\begin{array}{l}\text { Sum of } \\
\text { Squares }\end{array}$ & $\mathrm{df}$ & $\begin{array}{l}\text { Mean } \\
\text { Square }\end{array}$ & $\mathrm{F}$ & Sig. & $\beta$ & $\mathrm{t}$ & $\mathrm{p}$ & \\
\hline \multirow[t]{3}{*}{1} & Regression & 24.609 & 9 & 2.734 & 37.021 & .000 & & & \\
\hline & Residual & 8.863 & 120 & .074 & & & & & \\
\hline & Total & 33.472 & 129 & & & & & & \\
\hline \multirow[t]{10}{*}{1} & (Constant) & & & & & & & 3.869 & .000 \\
\hline & LCG & & & & & & .367 & 7.395 & .000 \\
\hline & IHNOO & & & & & & .237 & 2.539 & .012 \\
\hline & IONOO & & & & & & .020 & 0.364 & .716 \\
\hline & IHNDDB & & & & & & .307 & 4.449 & .000 \\
\hline & WEON & & & & & & .096 & 1.684 & .095 \\
\hline & SHN & & & & & & .100 & 1.097 & .275 \\
\hline & IES & & & & & & .145 & 2.324 & .022 \\
\hline & INES & & & & & & .111 & 1.926 & .056 \\
\hline & RILM & & & & & & .107 & 2.192 & .030 \\
\hline $\mathrm{R}$ & .857 & & & & & & & & \\
\hline $\mathrm{R}^{2}$ & .735 & & & & & & & & \\
\hline $\begin{array}{l}\text { Adj. } \\
\mathrm{R}^{2}\end{array}$ & .715 & & & & & & & & \\
\hline $\begin{array}{l}\text { Std. } \\
\text { Error }\end{array}$ & .272 & & & & & & & & \\
\hline
\end{tabular}

In order to identify workplace related content areas that need to be included in a cross cultural training and institutional orientation program, the multiple regression results in Table 4 found out that all the workplace adjustment factors contributed $55.3 \%$ variance to intention to stay and significant $[\mathrm{F}(9,124)=17.078, \mathrm{p}=.000]$ at 0.05 alpha level with a $3.2 \%$ decrease in the population value. Additionally, the information results showed that performance standards and expectations $(\beta=0.184, p=0.017)$, supervisory responsibilities $(\beta=0.241, p=0.000)$, teaching hours, administrative duties, faculty committees, community outreach $(\beta=0.300, p=0.000)$, creating the right classroom atmosphere $(\beta=0.149, p=0.030)$, and job security $(\beta=0.190, p=0.005)$ were important variables. Therefore, these variables are considered for content of a CCOT program.

Table 4: Multiple Regression and ANOVA Results for Workplace Adjustment Factors and Intention to Stay

\begin{tabular}{|c|c|c|c|c|c|c|c|c|c|}
\hline Model & $\begin{array}{l}\text { Sum of } \\
\text { Squares }\end{array}$ & $\mathrm{df}$ & $\begin{array}{l}\text { Mean } \\
\text { Square }\end{array}$ & $\mathrm{F}$ & Sig. & $\beta$ & $\mathrm{t}$ & $\mathrm{p}$ & \\
\hline \multirow[t]{3}{*}{1} & Regression & 19.101 & 9 & 2.122 & 17.078 & .000 & & & \\
\hline & Residual & 15.409 & 124 & .124 & & & & & \\
\hline & Total & 34.510 & 133 & & & & & & \\
\hline \multirow[t]{10}{*}{1} & (Constant) & & & & & & & 2.850 & .005 \\
\hline & ROCAA & & & & & & .050 & 0.642 & .522 \\
\hline & PSE & & & & & & .184 & 2.428 & .017 \\
\hline & SR & & & & & & .241 & 3.592 & .000 \\
\hline & TACCO & & & & & & .300 & 4.047 & .000 \\
\hline & CCA & & & & & & .149 & 2.197 & .030 \\
\hline & JS & & & & & & .190 & 2.832 & .005 \\
\hline & PCA & & & & & & .027 & 0.443 & .659 \\
\hline & ARTL & & & & & & .112 & 1.691 & .093 \\
\hline & IMS & & & & & & .074 & 1.085 & .280 \\
\hline $\mathrm{R}$ & .744 & & & & & & & & \\
\hline $\mathrm{R}^{2}$ & 0.553 & & & & & & & & \\
\hline $\begin{array}{l}\text { Adj. } \\
\mathrm{R}^{2}\end{array}$ & 0.521 & & & & & & & & \\
\hline $\begin{array}{l}\text { Std. } \\
\text { Error }\end{array}$ & 0.353 & & & & & & & & \\
\hline
\end{tabular}




\subsection{Text Analysis using Survey Monkey's Categorize feature}

In the questionnaire, participants were asked "based on your experience, please list the topics that should be included in any cross-cultural training/adjustment orientation program". This part of the questionnaire used openended questions in order to ensure that the respondents were not restricted to a set of predetermined likely answer choices. By using Survey Monkey's Categorize feature, the researcher was able to categorize and analyse participants' responses. Survey Monkey's Text analysis tool has proven to be an effective tool for creating and coding open-ended items in a questionnaire (Vaughn and Turner, 2016; Nelson, 2016; Patterson, 2016). In order to theme the participants' responses, the researcher assigned codes to their responses. These codes represented the themes that emerged during the text analysis. The following codes used were; "NGPESC" for "National Culture, Geographic, Political, and Economy Specific Content", "GEBSSI" for "Government, Education, Business, and Social Specific Information", "SCS" for "Stress and Coping Strategies", "ONJ" for "Organisation and the nature of the job", and "BPIR" for "Building positive Intercultural Relations". Table 5 shows the topics suggested by expatriate academics:

Table 5 Participants' opinions on the ideal content for a CCOT program

\begin{tabular}{|l|l|l|}
\hline $\begin{array}{l}\text { Participants' opinions on the ideal content of a cross cultural training and institutional orientation } \\
\text { program }\end{array}$ & Percentages & Number of participants \\
\hline Themes & $92.90 \%$ & 301 \\
\hline $\begin{array}{l}\text { National Culture, Geographic, Political, and } \\
\text { Economy Specific Content }\end{array}$ & $78.70 \%$ & 255 \\
\hline $\begin{array}{l}\text { Government, Education, Business, and Social } \\
\text { Specific Information }\end{array}$ & $62.65 \%$ & 203 \\
\hline Stress and Coping Strategies & $80.55 \%$ & 261 \\
\hline Organisation and the nature of the job & $75.93 \%$ & 246 \\
\hline Building positive Intercultural Relations & \\
\hline
\end{tabular}

The results shown in Table 5 indicate that majority of the participants $(n=301)$ representing 92.90\% suggested that "National Culture, Geographic, Political, and Economy Specific Content" should be included in a cross cultural training and institutional orientation program for expatriate academics in the United Arab Emirates, whereas on whiles only $62.65 \%(n=203)$ suggested that "Stress and Coping Strategies" as an important content area that needs to be included in a cross cultural training and institutional orientation program for expatriate academics in the United Arab Emirates. Content area related to "Organisation and the nature of the job" was suggested by $80.55 \%$ of the participants $(n=261)$ followed by "Government, Education, Business, and Social Specific Information" which was suggested by $78.70 \%$ of the participants $(n=255)$. "Building positive Intercultural Relations" which was suggested by $75.93 \%$ of the participants $(n=246)$. In summary, the top most important content areas considered relevant by the respondents fall within the following domains; National Culture, Geographic, Political, and Economy Specific Content; Organisation and the nature of the job; and Government, Education, Business, and Social Specific Information. Content area related to "Stress and Coping Strategies" was the least suggested by the respondents of the survey.

\section{Discussion}

\subsection{The Five Component Model}

After analysing the data from the questionnaires, interviews, and the review of literature, five distinct content areas were identified as important to be included in a CCOT program. These findings confirm the view of Selmer and Lauring (2016) who stated that an effective CCOT should include topics on local language skills, environmental briefing (information about the geography, climate, housing, schools) information about cultural orientation regarding cultural institutions, value system of host country assimilation of culture (brief episodes describing intercultural encounters, cultural and communication sensitivity. These five distinct content areas could be used in shaping the focus, content, and approach in developing a CCOT program. In many instances, these five content areas overlap with respect to the issues that they address, and are in some cases interrelated. The development of this model is based on the assumption that expatriate academics face cross cultural challenges related to general environment, everyday work related and social interaction. 
These content areas may operate as lenses for focusing on different aspects in CCOT programs within the context of higher education institutions in the UAE. These content areas are specific to the host country (UAE). The five content areas are:

1. National Culture, Religion, and Economy Specific Content;

2. Government, Education, Business, and Social Specific Information;

3. Stress and Coping Strategies;

4. Organisation and the nature of the job;

5. Building positive Intercultural Relations.

Figure 1 indicates an interrelation between the various content areas and the relationship between them for CCOT programs. It should also be noted that these content areas are suggestive. The next paragraphs below provide a detailed description of each content area.

Figure 1: A framework for shaping the focus and contentof cross-cultural orientation programs for Expatriate Academics in HEIs in the United Arab Emirates.

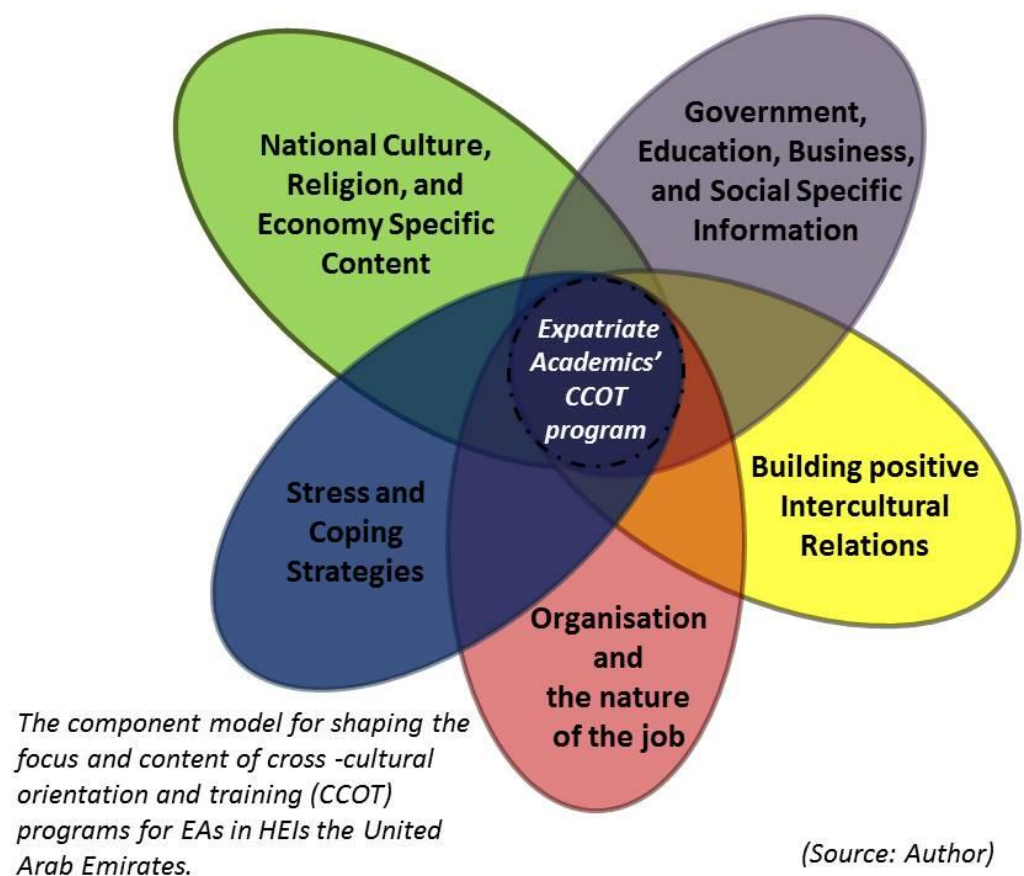

\subsubsection{National Culture, Religion, and Economy Specific Content}

This content area focuses on topics related to the United Arab Emirates' economic, geographic, political, religion, social, and cultural background. This content area will focus on the connection between culture and environmental change, and an individual's identity, and how this can impact their perceptions, stereotypes and attributions. The prime objective of this content area is not only to enhance the socio-cultural well-being, psychological well-being and satisfaction of new expatriate academics but also foster behavioral change and create positive intercultural perceptions and relations. For example, new expatriate academics given culture specific knowledge will enable them learn about the national culture. The importance of culture specific knowledge, including the Arabic language will also be emphasized here. With regards to the political and religious element within this content area, it must be noted that nations which derive their values from Islamic principles, uses the principles of their religion in their attitudes towards work ethics which in turn strengthens their faith (Ali and Al-Owaihan, 2008). In a study by Al Mazrouei and Pech (2015), it was found that Islamic religion and the Quran guides the work principles and the manner by which employees are managed in public organisations in the UAE. According to AlMazrouei and Pech (2015), this may be as a result of the nature in which UAE has held on to its long-established religion and religious values. Islamic principles are strongly followed by the UAE. 
In this paper, majority of the respondents held the belief that the UAE's culture is rooted on Islam, hence the need for allowing students to have prayer breaks or understanding the Ramadan timings are important. In this study, the respondents stressed the need for expatriate academics (particularly non-Muslims) to be ready to allow HCNs to have the opportunity to pray once every afternoon; and by this, expatriate academics would be enabling HCNs fulfill their religious obligation throughout the year.

Permitting a little extra time in the daily schedule to make room for break will help pave way for good working relationships. In the bid to achieving institution's goals, expatriate academics should not forget that they are working in a culture which is predominately of the Islam origin hence they should not impose their own cultural values on the local (HCN) staff and students.

\subsubsection{Government, Education, Business, and Social Specific Information}

This component focuses on topics related to the government policies, children's schooling information, business procedures in regards to certain permits, and or services etc. It will also include information on social clubs or expatriate social gathering. New expatriate academics need to know the government and business procedures in obtaining certain services. Such information and services are very relevant to enabling a smooth transition for the new expatriate academic. By providing information covering areas on how to successfully and smoothly obtain certain permits or services, new expatriate academics will have a much smoother settling and adjustment experience.

\subsubsection{Organisation and the nature of the job}

This component focuses on topics related to the organisation's strategic goals, vision, values, mission, and culture. Additionally, new expatriate academics will also be giving information on the nature of the job, and students. The common activities for this content area will include; lecturing/information giving, informal sessions (with expatriate academics who been in the institution for a longer time); informal sessions (with host country nationals); and self-assessment exercises. The objective of this content area is to enhance the socio-cultural wellbeing, psychological well-being and satisfaction of new expatriate academics.

\subsubsection{Stress and Coping Strategies}

Forster (1997) and Tung (1981) advance an argument that stress and uncertainty that expatriates undergo are the main cause of cross-cultural adjustment issues. This component focuses on topics related to stress and coping strategies that new expatriate academics could use when they are confronted with environmental pressure. Chang and Taylor (2014) define coping strategies as "proactive behaviours adopted by individuals to deal with strain when confronted with environmental pressure, or perceived threat from stressors" (p.2). Coping strategies help enable and sustain job satisfaction and also helps create to a sense of physical well-being (Morris and Long, 2002). This content area is relevant because it views adjustment as a stress causing condition and emphasises on the significance of stress management and developing constructive coping mechanisms. Based on the literature review, data analysis, and responses from the interview, these were the suggested topics that fell under this content area:

a) How to handle a student complaint

b) Classroom management

c) Stress management

d) Social support identification

e) Coping strategies

f) Process

g) Symptoms of 'culture shock'

h) Cognitive reframing

i) Coping with students negotiating for marks

The learning outcome of this content area is to foster behavioural change and enhance the socio-cultural and psychological well-being of new expatriate academics.

\subsubsection{Building positive Intercultural Relations}

According to Welker, Slatcher, Baker, and Aron (2014, p.1), "building personal relationships with out-group members are an important catalyst to building positive intergroup attitudes". 
In this paper, the respondents also suggested that orientation programs should be jointly developed and facilitated by both Emiratis and expatriates academic staff. Emirati input and involvement in developing and implementing the orientation programs is very important. According to Toh and Srinivas (2011) "information sharing between expatriate and host country national ( $\mathrm{HCN})$ employees is strategically significant" (p.1). Empirical evidence (Toh and DeNisi 2007; Varma, Budhwar, Pichler and Biswas 2009) shows that Host Country Nationals can positively contribute to the adjustment of expatriates.

In a study (Mahajan and Toh, 2014) involving 350 expatriates working in the U.S., it was shown that expatriates who received support from Host Country Nationals who were co-workers reported higher levels of work and interaction adjustment.

Hence, in this case, the involvement of $\mathrm{HCN}$ co-workers in the development and facilitation of orientation and training programs will bring an Emiratis perspective on what can enhance expatriate adjustment. This content area will focus on the knowledge, skills, and awareness in perceptual processes behind building positive intergroup relations (as well as stereotypes \& attributions). The importance of culture specific knowledge, including language fluency and social skills will also be re-emphasized within this content area. Among the several objectives of this content area, is to build positive intercultural perceptions and relations among expatriate academics, staff, HCNs, and students. This content area also will focus on the connection between culture and environmental change and an individual's identity, and how they can impact their perceptions, stereotypes and attributions.

\section{Conclusions and Recommendations}

Research findings support the claim that certain knowledge and skills are significant for positive cross-cultural experiences (Ruben and Kealey, 1979; Black and Mendeanhall, 1990). The finding also support the claim that CCOT can be effective depending on the host nation, the individual expatriate and the contextual factors of the foreign assignments (Selmer, 2004). Tung (1981) pointed out that the CCOT programmes require a certain extent of modification based on the nature of the overseas assignment and the host culture. By adopting appropriate and adequate CCOT programs, organizations could save a lot of money. The five component models will help in shaping the focus and content of CCOT programs for expatriate academics in HEIs in the United Arab Emirates which will subsequently positively enhance their cross cultural adjustment experience. This model is meant to serve as a reminder of how significant it is for higher education administrators, line managers, and HR practitioners to reflect on the many variables that contribute to developing and implementing a comprehensive CCOT programs for expatriate academics. It should be noted that the suggestive model that is based on the responses of the participants in this study, and information gathered from the review of the literature hence might not be generalizable. This is not a "one-size fits all" model but rather should serve as a conceptual model which should be considered as the theoretical onset for a further empirical study in order to further empirically test and validate it. Just like all other CCOT development decisions, your learners, their needs, and the preferred learning styles should dictate where you start and how you choose to address each of the content areas highlighted above. Perhaps a more comprehensive model could be derived by collecting from all key stakeholders such as students, HR professionals, HCNs, recruitment agencies, cross cultural training specialist and consultants, and managers in HEIs in the UAE. The author also suggests that further empirical studies be carried out to validate this model. It should be noted that these five content areas do not necessarily have to be addressed independently of one another but rather should serve as a guide in ensuring that all the relevant content areas have been covered completely during the period of a CCOT program.

\section{References}

Ali, A. J., \& Al-Owaihan, A. (2008). Islamic work ethic: a critical review. Cross culturalmanagement: An international Journal, 15(1), 5-19.

AlMazrouei, H., \&Pech, R. J. (2015).Working in the UAE: expatriate management experiences. Journal of Islamic Accounting and Business Research, 6(1), pp.73-93.

Alshammari, H. (2013). The adjustment of self-initiated expatriate academics in higher education institutions in Saudi Arabia (Doctoral dissertation, RMIT University).

Altbach, P. G. (2016). Global Perspectives on Higher Education. John Hopkins University Press.

Badry, F., \& Willoughby, J. (2015). Higher education revolutions in the Gulf: Globalization and institutional viability. Routledge. 
Berry, J. W. (2005). Acculturation: Living successfully in two cultures. International journal of intercultural relations, 29(6), 697-712.

Bhaskar-Shrinivas, P., Harrison, D. A., Shaffer, M. A. \&Luk, D. M. (2005). Input- based and time-based models of international adjustment: Meta-analytic evidence and theoretical extensions. Academy of Management Journal, 48(2), pp.257-281.

Black, J. \& Stephens, G. (1989).The influence of the spouse on American expatriate adjustment and intent to stay in Pacific Rim overseas assignments.Journal of Management, 15(4), pp. 529-544.

Black, J.S. and Mendenhall, M. (1990) Cross-cultural training effectiveness: A review and theoretical framework for further research. Academy of Management Review, 15(1), pp.113-136.

Caligiuri, P.M. (2000a). "Selecting Expatriates for Personality Characteristics: A Moderating Effect of Personality on the Relationship Between Host National Contact and Cross-cultural Adjustment", Management International Review, Vol.40 No.1, pp. 61-80.

Caligiuri, P.M. (2000b). "The big five personality characteristics as predictors of expatriate's desire to terminate the assignment and supervisor-rated performance", Personnel Psychology, Vol. 53 No. 1, pp. 67-88.

Caligiuri, P.M. (2000c). Selecting expatriates for personality characteristics: A moderating effect of personality on the relationship between host national contract and cross-cultural adjustment. Management International Review, 40(1), pp.61-80.

Caligiuri, P., \&Tarique, I. (2016).Cultural agility and international assignees' effectiveness in cross-cultural interactions. International Journal of Training and Development, 20(4), 280-289.

Caligiuri, P.M., Phillips, J., Lazarova, M., Tarique, I. and Burgi, P. (2001). The theory of met expectations applied to expatriate adjustment: The role of cross-cultural training. International Journal of Human Resource Managment, 12(3), pp.357-372.

Chan, Ka Wai (2015). An Exploration of Cross-cultural Adjustment and Job Satisfaction among Primary School Native-speaking English Teachers in Hong Kong.PhD, Durham University.

Chan, Y.M. (2008) A study on the life adjustment and teaching experience of foreign teachers in Taiwan - A case study in Taitung County. Unpublished Master's thesis.National Taitung University.

Chang, K., \& Taylor, J. (2014). Do your employees use the right stress coping strategies. International Journal of Commerce and Strategy, 5(2), 99-116.

Chu, Chau, Kan (2009). Cross-Cultural Adjustment of Native English Teachers In Hong Kong: An Investigative Study, Durham theses, Durham University.

Clarke, M. (2015). Working Abroad in Higher Education: If Only I Knew.Partridge Publishing Singapore.

Deshpande, S.P. and Viswesvaran, C. (1992) "Is Cross-cultural Training of Expatriate Managers Effective? A Meta-analysis" International Journal of Intercultural Relations, 16, pp. 295-310.

Forster, N. (1997). The persistent myth of high expatriate failure rates: A reappraisal. International Journal of Human Resource Management, 8(4), pp.414-433.

Garrett, R., Kinser, K., Lane, J. E., \& Merola, R. (2016). International branch campuses: Trends and developments, 2016. The Observatory on Borderless Education and C-BERT (Cross-border Education Team), London, UK.

Gullekson, N., \& Dumaisnil, A. (2016). Expanding horizons on expatriate adjustment: A look at the role of emotional display and status. Human Resource Management Review, 26(3), 260-269.

Hechanova, R., Beehr, T. A., \& Christiansen, N.D. (2003). Antecedents and consequences of employees' adjustment to overseas assignment: A meta-analytic review. Applied Psychology: An International Review, 52, pp.213-236.

Hofstede, G.H. (2001). Culture's Consequences: Comparing Values, Behaviours, Institutions and Organizations Across Nations. Sage: Thousand Oaks.

Isakovic, A., \&Forseth Whitman, M. (2013).Self-initiated expatriate adjustment in the United Arab Emirates: a study of academics. Journal of Global Mobility, 1(2), 161-186.

Johnson, J.P., Lenartowicz, T. and Apud, S. (2006). Cross-cultural competence in international business: towards a definition and a model. Journal of International Business Studies, 37(4), pp.525-543.

Knight, J. (2011). Education hubs: A fad, a brand, an innovation?. Journal of Studies in International Education, 15(3), 221-240.

Knight, J. (2013). The changing landscape of higher education internationalisation-for better or worse? Perspectives: Policy and practice in higher education, 17(3), 84-90. 
Kraimer, M., Bolino, M., \& Mead, B. (2016). Themes in expatriate and repatriate research over four decades: What do we know and what do we still need to learn? Annual Review of Organizational Psychology and Organizational Behavior, 3, 83-109.

Kreber, C., \&Hounsell, J. (2014).Being an international academic: A phenomenological study of academic migrants adjusting to working and living in Scotland. Academic Mobility (International Perspectives on Higher Education Research, Volume 11) Emerald Group Publishing Limited, 11, pp.9-33.

Liao, W. J. (2010). The cross-cultural adjustment of EFL expatriate teachers in Taiwan.Doctoral dissertation, University of Bedfordshire, United Kingdom.

Mahajan, A., \&Toh, S. M. (2014).Facilitating expatriate adjustment: The role of advice-seeking from host country nationals. Journal of World Business, 49(4), 476-487.

Mahrous, A.A., \& Ahmed, A.A. (2010).A cross-cultural investigation of students' perceptions of the effectiveness of pedagogical tools.Journal of Studies in International Education, 14(3), 289-306.

Mendenhall, M., Kuhlmann, T., Stahl, G. \&Osland, J. (2002). Employee development and expatriate assignments: A review of the expatriate adjustment theory literature. In M. Gannon \& K. Newman (Eds.), Handbook of cross-cultural management (pp. 155-183). CA: Thousand Oaks.

Miller, P.W (2009). Reconstructing teacher identities: shock, turbulence, resistance and adaptation in Caribbean teacher migration to England. Education, Knowledge \& Economy, 3(2), 97-105.

Miller, P. W. (2010). Survival from within. Journal of the University College of the Cayman Islands, 4.

Ministry of Higher Education and Scientific Research (MOHESR).(2014). The UAE higher education factbook, 2013/2014. Retrieved from www.mohesr.gov.ae/En/ServicesIndex/Documents/UAEfactbook24Feb-enCDversion.pdf

Morris, J. E. and Long, B. C., (2002). Female Clerical Workers' Occupational Stress: The Role of Person and Social Resources, Negative Affectivity and Stress Appraisal, Journal of Counselling Psychology, 49(4), $395-410$.

Musselin, C. (2004). Towards a European academic labour market. Some lessons drawn from empirical studies on academic mobility. Higher Education, 48(1), 55-78.

Nelson, J. (2016). The Practice of Survey Research Theory and Applications: A Review. The Qualitative Report, 21(4), pp.643.

Palmer, B. M. (2013). Culture in The EFL Classroom: Western Instructors and Arab Students in the $U A E$ (Doctoral dissertation), American University of Sharjah.

Patterson, S. L. (2016). The effect of emotional freedom technique on stress and anxiety in nursing students: A pilot study. Nurse education today, 40, pp.104-110.

Richardson, J. (2000), "Expatriate academics in the globalized era: the beginnings of an untold story?" Asia Pacific Business Review, Vol. 7 No. 1, pp. 125-150.

Richardson, J. and McKenna, S. (2002), "Leaving and experiencing: why academics expatriate and how they experience expatriation", Career Development International, 7(2), pp. 67-78.

Ruben, B.D. and Kealey, D.J. (1979).Behavioural assessment of communication competency and the prediction of cross-cultural adaptation.International Journal of Intercultural Relations, 3, pp.15-47.

Sanderson, K. (2014). Academic expatriation: Experiences from within the United Arab Emirates. In Academic Mobility (International Perspectives on Higher Education Research, Volume 11) Emerald Group Publishing Limited, 11, pp.175-196.

Selmer, J. (2004) Organizational abode and the effectiveness of cross- cultural training of business expatriates. Submitted for presentation at the SAM/IFSAM VIIth World Congress, Management in a world of diversity and change, 5-7 July, 2004. Goteborg, Sweden.

Selmer, J., \&Lauring, J. (2016). Work engagement and intercultural adjustment. International Journal of Cross Cultural Management, 16(1), 33-51.

McNulty, Y., \& Selmer, J. (Eds.).(2017). Research Handbook of Expatriates.Edward Elgar Publishing.

Selmer, J. and Lauring, J. (2011), "Expatriate academics: job factors and work outcomes", International Journal of Manpower, 32(2), pp. 194-210.

Swagler, M.A. and Ellis, M.V. (2003) Crossing the distance: Adjustment of Taiwanese graduate students in the United States.Journal of Counseling Psychology, 50(4), pp.420-437.

Toh, S.M. and DeNisi, A.S. (2005).A local perspective to expatriate success.Academy of Management Executive, 19(1), pp.132-146. 
Toh, S. M., \& Srinivas, E. S. (2012). Perceptions of task cohesiveness and organizational support increase trust and information sharing between host country nationals and expatriate coworkers in Oman. Journal of World Business, 47(4), 696-705.

Tripathi, P., \&Mukerji, S. (2008). Access and equity to education in India through synergy of conventional and ODL systems: A step towards democratization of education. Open Praxis, 9(9).

Tung, R. (1981). Selecting and training of personnel for overseas assignments.Columbia Journal of World Business, 16(1), pp.68-78.

Tung, R.L. (1982a). Selection and training procedures of U.S., European, and Japanese multinationals.California Management Review, 25 (1), pp.57-71.

Tung, R.L.(1982b), "Selection and Training Procedures of U.S., European, and Japanese Multinationals", Columbia Management Review, 25(1), pp. 57-71

Varma, A., Pichler, S., Budhwar, P., \& Biswas, S. (2009). Chinese host country nationals' willingness to support expatriates: The role of collectivism, interpersonal affect and guanxi. International Journal of Cross Cultural Management, 9(2), 199-216.

Vaughn, P., \& Turner, C. (2016). Decoding via Coding: Analyzing Qualitative Text Data Through Thematic Coding and Survey Methodologies. Journal of Library Administration, 56(1), pp.41-51.

Ward, C., Leong, C.H. and Low, M. (2004) Personality and sojourner adjustment: An exploration of the big five and the cultural fit proposition.Journal of Cross-Cultural Psychology, 35(2), pp.137-151.

Welker, K. M., Slatcher, R. B., Baker, L., \& Aron, A. (2014).Creating positive out-group attitudes through intergroup couple friendships and implications for compassionate love. Journal of Social and Personal Relationships, 31(5), 706-725.

Zhang, L. E., \&Peltokorpi, V. (2016). Multifaceted effects of host country language proficiency in expatriate cross-cultural adjustments: a qualitative study in China. The International Journal of Human Resource Management, 27(13), 1448-1469. 